\title{
FAILURES OF INTERACTION BETWEEN POWERED TWO-WHEELER RIDERS AND CAR DRIVERS IN URBAN ACCIDENTS
}

\author{
P. VAN ELSLANDE \& J.-Y. FOURNIER \\ The French Institute of Science and Technology for Transport, Spatial Planning, \\ Development and Networks (IFSTTAR), France.
}

\begin{abstract}
The users of powered two-wheeler (PTW) are facing everywhere in the world a road risk significantly higher than car users, especially in towns. This is particularly the case in France, where the risk of death per kilometre travelled for two-wheeler rider is over 20 times that of motorists. This risk is linked to the intrinsic vulnerability of these road users due to a lack of protection by a coachwork, but it also highlights some accidents configurations that deserve to be analysed in depth to understand their mechanisms and factors, and to set countermeasures. The present paper is based on the results of a previous comparative analysis of accidents involving PTWs occurred in urban and extra-urban areas, to understand in more detail the specific problems generated by urban traffic situations. It aims to deepen the question of the interactions that take place between the driving failures of the protagonists (notably PTW riders and car drivers) involved in urban accidents. 565 accident cases of this type are examined in more detail. The study of these accidents shows a strong interaction between the anticipation failure by the rider and a perception failure by the car driver. The process of this interaction consists in the car drivers being surprised by the presence and/or an unexpected behaviour of the PTW driver; and in return the manoeuvre undertaken by the car driver misleads the expectations of the PTW driver who was sure to have been seen. Solutions to this critical malfunction scenario are thought to be found in training and communication of different road user, and in an urban road network that offers greater visibility and predictability of behaviour.

Keywords: accident, anticipation, human error, motorcycling, perception, powered two-wheeler, traffic safety.
\end{abstract}

\section{INTRODUCTION}

The powered two-wheeler (PTW) is a means of transport increasingly popular in Europe as in many countries of the world, especially for its potential to escape traffic congestion. But the use of these vehicles is still now, despite a general decline in the accident rate, a particularly dangerous transport mode and their users are still highly vulnerable to the risk of collision. In OECD countries, PTW riders represent on average 17\% of total traffic fatalities, while PTWs account for about $8 \%$ of the motorised vehicle fleet [1]. In France, PTW users victims of traffic crashes represent, in 2014, over $23 \%$ of the total killed on the road (18\% for motorcycles, $5 \%$ for mopeds), and over $37 \%$ of hospitalized victims ( $24 \%$ for motorcycles, $13 \%$ of mopeds), even though the share of these vehicles in the total traffic in terms of mileage is estimated less than $2 \%$ [2]. Consequently, the risk of being killed when riding on a PTW in France is over 23 times the risk per kilometre driven by a car. And although many actions are performed towards PTW safety, they are struggling to significantly reduce this excess risk.

This difficulty in progress shows the limits of a too general approach to the issue of PTW safety, which is often limited to a statistical observation and sometimes relies on received

This paper is part of the proceedings of the 22nd International Conference on Urban Transport and the Environment (Urban Transport 2016)

www.witconferences.com 
ideas. It demonstrates a real need for research on the foundations of this insecurity from the perspective of defining measures that address the specificities and the needs of each participant of the traffic system. Of course, the always evoked problem of the vulnerability inherent in this mode of transport is a major issue that still calls over mitigation measures. But this issue should not mask other difficulties equally at play. It must be taken into account the fact that PTWs have a specific dynamic behaviour which sometimes causes greater control difficulties in interactions with the road infrastructure. One must also consider the fact that these vehicles take a special place within the overall traffic, with particular template, driving and performances (in terms of speed, acceleration, manoeuvrability, etc.) that can generate particular difficulties of interaction with the other users of the same road space [3]. The analysis of these difficulties of interaction can be seen as a key condition for understanding the accident mechanisms of PTW and for improving the safety of their integration into the traffic system.

And this question is particularly relevant in urban environment where PTW traffic is a growing issue and consequently also the difficulties of interaction with other road users. The problem of PTW urban crashes is widespread in Europe where the proportions of motorcycle and moped rider fatalities in town are considerably larger than that for car occupants [4]. This is even more prevalent in France where nearly one quarter of accidents occurred in an urban area, in 2014, involved a motorcycle. Another significant data is that $81.9 \%$ of PTW injury crashes and $40.2 \%$ of PTW fatal crashes occurred in town [2]. Such results appeal for a thorough analysis of the mechanisms of these accidents.

Prior research work had concentrated on describing the processes of PTW accidents occurred in the city in comparison with those in the countryside [5]. This analysis helped identify a number of specific difficulties that PTW drivers encounter in an urban environment. It also showed that car drivers were showing some particular problems when they were confronted with PTWs. The purpose of the present paper is to go further into the knowledge of urban PTW accidents by focalizing on a recurring configuration identified: the interaction between, on the one side, 'prognosis failures' (i.e. errors of anticipation) committed by motorcyclists' vis-à-vis car drivers' behaviour and, on the other side, perception failures committed by car drivers visà-vis PTWs. It is the most represented combination of failures in accidents resulting from an interaction between a car and a motorcycle occurring in urban areas. We seek here to identify the conditions of production of these accidents, both from the perspective of motorcyclists and from the point of view of motorists, by analysing driver and rider errors, factors of their errors, the respective levels of involvement and the contexts in which these interactive driving failures occur. By confronting the shortcomings of each other, we try to establish how motorists and motorcyclists sometimes contribute complementarily to accident production.

\section{MODEL AND METHOD}

\subsection{Human driving failures in traffic accidents}

The concept of 'human functional failure' [6] seeks to operationally account for the difficulties encountered by road users in the exercise of their driving activity, which commonly are placed under the term 'human error'. This notion of functional failure characterizes the momentary unsuccess in a given context of one or more perceptual, cognitive and active functions that normally lead to efficient driving. It marks the point of rupture from a situation regulated and an uncontrolled situation. It shows the limits of adaptive procedures set up by drivers to compensate for the difficulties encountered, whether they come from human, environmental or vehicles parameters. 
One purpose of the definition of these failures is to clearly distinguish the effect of the cause, and in particular to avoid the common-sense confusion between 'human error' and the 'human factor of error' Thus, a certain functional failure (e.g. poor detection) may result from different levels of factors related to infrastructure (e.g. a signal impeding visibility), the vehicle (e.g. a blind spot) and the driver (e.g. poor vision, a moment of distraction, etc.). And mixing the error and its causes severely limits the effectiveness of policy measures to be implemented (e.g. by imposing a visual acuity test to combat the problem of blind spots, etc.).

The human functional failures model also leads to clearly differentiate the term 'error' from 'fault' and therefore to differentiate from an approach which aims at attributing responsibility rather than understanding the problems met by the drivers. Apart from justice and insurance purposes, an analysis of the accident phenomena in terms of responsibility can be useful for statistical studies of the risks but becomes excessively reductive for in-depth understanding of the problems at play. From the perspective of traffic safety action, it offers, whatever the problem, only one opportunity of solution: the sanction. However it is often necessary to properly determine the origins of a problem in order to define well-adapted measures. For instance, when dealing with a driver who 'violates a loss of right of way', the most appropriate action will not be the same - whether he did it deliberately or due to a perception problem or because of a slowness of action. Moreover, a driver, even 'not responsible' of the accident, can nevertheless be helped if the difficulties he has encountered can be qualified in the same way as for the other. In an ergonomic orientation, the identification of malfunctions and their combinations of factors allows to widen the range of solutions, from the side of road planning, traffic management, improvement of training, better adaptation of vehicles to their users, etc., with the purpose to ensure avoiding the implementation of unwanted behaviours, including errors production.

\subsection{Method}

The research work is based on a detailed analysis of a sample of 565 road accident protocols involving at least one motorcycle. This sample was built from a random sampling of accident cases gathered at the national level by IFSTTAR (France) for research purposes, this sampling being representative of the injury accidents reported in France by the police services. The accident reports include information obtained at the accident scene and, later on, statements by the persons involved and the witnesses, photos, a map of the accident site with the situation of the collision point and position of the vehicles after the crash, medical data on the injuries, etc. The analysis was conducted in a way to extracting systematic information on the typical accident configurations, the combinations of human-vehicle-environment factors involved and the resulting drivers' errors and other human failures participating in the accident process.

This analysis made use of both an accident phase model [7], allowing the segmentation of the accident process in a systematic way, and a human failure model (HFF), allowing the classification of the driving functional failures (i.e. human errors and capacity exceeding) found in traffic accidents and of the factors of these failures [6]. The HFF model distinguishes five major functional categories within which can be identified the incapacity of a function (perceptive, diagnostic, prognostic, decision making and action taking) to overcome a difficulty encountered by the driver. A sixth category deals more with a problem of general aptitude to drive than the specific capacity to handle a difficulty: these 'generalized failures' 
correspond to an alteration of the entire functional chain (i.e. on the perceptive, cognitive and psychomotor levels), making the driver unable to manage the slightest difficulty encountered on his route (e.g. falling asleep). These different categories of failures are delineated into 20 types (Table 1).

\section{RESULTS}

This section is devoted to the analysis of a sample of 271 accidents involving a problem of anticipation ('prognosis failure') encountered by a motorcycle rider when confronted with a car in town, this kind of driving failure being the most frequent in these accidents as shown in a previous study [3]. These accidents are compared to a sample of 294 accidents involving another problem, i.e. another kind of failures committed by a motorcycle rider in a similar context.

This analysis relies upon the description of the different variables characterizing the production of the accidents, including the type of driving failure, the factors and circumstances of the failures for both the motorcyclist and the opponent motorist.

Table 1: Distribution of human functional failures (from Van Elslande et al. [6]).

\begin{tabular}{|c|c|}
\hline $\begin{array}{l}\text { Failures } \\
\text { categories }\end{array}$ & Types of failures \\
\hline \multirow{5}{*}{ Perception } & Per1: Non-detection in a situation of limited visibility \\
\hline & $\begin{array}{l}\text { Per2: Information acquisition focused on a partial component of the situ- } \\
\text { ation }\end{array}$ \\
\hline & Per3: Cursory or hurried information acquisition \\
\hline & Per4: Momentary interruption in information acquisition \\
\hline & Per5: Neglect of information-seeking requirements \\
\hline \multirow{4}{*}{ Diagnosis } & Diag1: Poor evaluation of a temporary road difficulty \\
\hline & Diag2: Erroneous evaluation of the size of a time/space gap \\
\hline & Diag3: Mistaken understanding of how a site functions \\
\hline & Diag4: Mistaken understanding of another user's manoeuvre \\
\hline \multirow{3}{*}{ Prognosis } & Pro1: Expectation by default of no manoeuvre by another user \\
\hline & Pro2: Active expectation of adjustment by another user \\
\hline & Pro3: Expectation of no obstacle \\
\hline \multirow{3}{*}{$\begin{array}{l}\text { Decision } \\
\text { making }\end{array}$} & Dec1: Violation directed by the characteristics of the situation \\
\hline & Dec2: Deliberate violation of safety rule \\
\hline & Dec3: Violation by automatism \\
\hline \multirow{2}{*}{ Action taking } & Exe1: Poor controllability when faced with an external disturbance \\
\hline & Exe2: Guidance problem \\
\hline \multirow{3}{*}{ Overall failure } & Gen1: Total loss of psychophysiological capacities (e.g. falling asleep) \\
\hline & Gen2: Alteration of all sensorimotor and cognitive capacities \\
\hline & Gen3: Overstretching cognitive capacities \\
\hline
\end{tabular}


3.1 Motorcyclist's prognosis failures when confronted with a car in town

\subsubsection{Types of prognosis failure}

Three types of problems correspond to prognosis failures, which are defined as the following.

The first prognosis failure refers to 'Expecting another user not to perform a manoeuvre' (Pro1 failure, Table 2). In the absence of cues to the contrary, the riders who had the right of way at an intersection did not expect a non-priority user who was stationary to start moving forward and were surprised by this unexpected manoeuvre.

The second one encompasses 'Actively expecting another user to take regulating action' (Pro2 failure). This second level of failure at the prognosis processing stage deals with the expectancy of a regulation from the part of another user whom the driver is in interaction with. From his erroneous expectations, based on what he is used to, and despite observing disturbing signs, the driver rules out the possibility of a critical evolution of the situation encountered. As a result, he does not execute a preventive driving strategy adapted to the predictable critical evolution.

The third prognosis failure corresponds to 'Expecting no perturbation ahead'. It accounts for the cases where drivers rely on their expectations to drive in a way that will make them inapt to adapt when meeting a difficulty, for example, by going partly or totally on the path of another road user, sometimes just by speeding. The mechanism of this failure is unilaterally linked to the driver's adopting a mode of behaviour that does not integrate the possibility of encountering any impediment on his route, despite a lack of visibility. Instead of prompting him to take particular precautions, the restricted visibility seems to encourage the driver to take the line that 'If I don't see anything, it means there is nothing'.

As shown in Table 2, it is essentially the first type that characterizes the prognosis failures committed by motorcycle drivers in urban accidents, reflecting more a 'by default' expectancy than an oriented anticipation of the behaviour of the opponent car. As discussed below, this type of failure is usually due to excessive confidence in their 'right of way' coupled with a lack of attention paid to the other road users.

\subsubsection{Level of involvement}

It is noticeable in Table 3 that PTW drivers are much less at the origin of road conflicts ('primary contributing' status) when they make a prognosis mistake than when committing another type of functional failure. But, in return, they have a much stronger involvement as 'secondary contributing' (61.7\% for prognosis failure versus $25.5 \%$ for other failures). This result reflects the fact that difficulties to anticipate situation changes often lead the PTW riders not to adapt their behaviour to the mistakes of others, rather than causing by themselves problems for others, as is the case for other categories of failures they commit.

Table 2: Distribution of motorcyclists' prognosis failures.

\begin{tabular}{lcc}
\hline Type of prognosis failure & $\mathrm{n}$ & $\%$ \\
\hline $\begin{array}{l}\text { Pro1 failure - Expecting another user not to perform a } \\
\text { manoeuvre }\end{array}$ & 193 & 71.5 \\
$\begin{array}{l}\text { Pro2 failure - Actively expecting another user to take } \\
\text { regulating action }\end{array}$ & 43 & 15.9 \\
Pro3 failure - Expecting no perturbation ahead & 34 & 12.6 \\
\hline
\end{tabular}


Table 3: Riders' level of involvement for prognosis failures versus other failures.

\begin{tabular}{lcccc}
\hline Level of involvement & $\begin{array}{c}\text { Prognosis } \\
\text { failures }\end{array}$ & $\%$ & Other failures & $\%$ \\
\hline Primary contributing & 85 & 31.6 & 194 & 66.0 \\
Secondary contributing & 166 & 61.7 & 75 & 25.5 \\
No contributing & 18 & 6.7 & 25 & 8.5 \\
Total & 269 & 100 & 294 & 100 \\
\hline
\end{tabular}

\subsubsection{Rider's age}

Age does not seem to have an influence on the propensity to commit prognosis failures (Table 4). Perhaps more surprisingly, as we shall see, we did not observe an influence of experience on the propensity to commit this type of errors.

\subsubsection{Driving situation}

The prognosis failures tend to occur more often at intersections than other failures (Table 5). It is in these situations that motorcyclists are most often surprised by the behaviour of others. Most of the time, the rider was just in his lane (without overtaking or filtering) when arriving at the intersection where he has the right of way. Out of intersections, the situations most favourable to prognosis error are lane changing, U-turn and parking manoeuvres by the opponent car. Yet intersection situations are more prone to PTW rider's prognosis failures than to other types of failures.

\subsubsection{Factors of driving failures}

An overall analysis of the factors that contribute to motorcyclists' failures (Table 6) shows that their prognosis problems are rather coming from psychological variables such as overconfidence in their 'priority' status (38.7\% versus $15.3 \%$ for other failures), in the signals they transmit to others $(8.5 \%$ versus $1.4 \%)$ and in the fact that they are seen by others (39.9\% versus $8.2 \%)$.

The data also confirms that the surprising behaviour of the opponent driver (ambiguous, atypical, without signals) is a factor that contributes significantly more to the prognosis errors than to other types of errors: at least one of these elements is observed in $54 \%$ of the cases of prognosis failure, against $38.8 \%$ for other types of failure.

Table 4: Types of failures according to rider's age.

\begin{tabular}{lcc}
\hline & Prognosis failures & Other failures \\
\hline Rider's age mean & 36.23 & 36.15 \\
\hline
\end{tabular}

Table 5: Types of failures according to the driving situation.

\begin{tabular}{lcccc}
\hline & $\begin{array}{c}\text { Prognosis } \\
\text { failures }\end{array}$ & $\%$ & $\begin{array}{c}\text { Other } \\
\text { failures }\end{array}$ & $\%$ \\
\hline Intersection & 140 & 51.7 & 123 & 41.8 \\
Out of intersection & 131 & 48.3 & 171 & 58.2 \\
Total & 271 & 100 & 294 & 100 \\
\hline
\end{tabular}


Table 6: Most frequent factors of riders' failures.

\begin{tabular}{|c|c|c|}
\hline & $\begin{array}{l}\text { Prognosis } \\
\text { failure (\%) }\end{array}$ & $\begin{array}{c}\text { Other failures } \\
(\%)\end{array}$ \\
\hline Vigilance (somnolence) & 1.1 & 4.8 \\
\hline Alcohol ( >à 0.5 g/l) & 1.5 & 8.8 \\
\hline Panic/no reaction & 1.1 & 4.8 \\
\hline Inattention & 5.5 & 13.6 \\
\hline Distraction & 1.5 & 6.1 \\
\hline Inexperience of driving & 3.7 & 4.8 \\
\hline Over experience of the situation & 17.7 & 21.1 \\
\hline Rigid attachment to right of way & 38.7 & 15.3 \\
\hline Over confidence in signs given to others & 8.5 & 1.4 \\
\hline Temporal constraint & 2.5 & 14.3 \\
\hline Banalization of the situation & 20.3 & 22.4 \\
\hline Speed too high for the situation & 18.8 & 18.4 \\
\hline Speed above the limits & 4.1 & 8.5 \\
\hline Too small gap & 4.8 & 7.1 \\
\hline Risky driving (for fun, transgression, etc.). & 1.5 & 11.9 \\
\hline Illusion of visibility (believe to be seen by others) & 39.9 & 8.2 \\
\hline Obstruction to visibility & 8.1 & 21.8 \\
\hline $\begin{array}{l}\text { Poor visual saliency of the protagonist (small size, lack of } \\
\text { contrast) }\end{array}$ & 3.3 & 5.1 \\
\hline $\begin{array}{l}\text { Absence of signals indicating the manoeuvre of another } \\
\text { vehicle }\end{array}$ & 12.9 & 3.7 \\
\hline Ambiguous signals given by another road user & 6.6 & 4.8 \\
\hline Surprising manoeuvre by another road user & 16.6 & 11.9 \\
\hline Illegal manoeuvre by another road user & 21.4 & 11.9 \\
\hline Hampering behaviour by another road user & 3.3 & 7.5 \\
\hline
\end{tabular}

In return, there is less often an influence of variables related to attention, vigilance and risk-taking. The visibility masks do not show either a significant impact on these difficulties of prognosis or the variables dealing with experience.

Thus, the central frame of motorcyclists' prognostic failures in a situation of interaction with a motorist correspond to the combination between the rider's overconfidence vis-à-vis his own expectations, meeting a motorist's unexpected behaviour which challenges this certainty. As we shall see in the next section, this unexpected behaviour also comes from a specific failure committed by car drivers when meeting PTWs. 
Table 7: Distribution of motorists' failures.

\begin{tabular}{lcccr}
\hline $\begin{array}{l}\text { Failures category } \\
\text { (car driver) }\end{array}$ & $\begin{array}{c}\text { Confronting a } \\
\text { motorcyclist } \\
\text { committing a } \\
\text { prognosis failure }\end{array}$ & $\%$ & $\begin{array}{c}\text { Confronting a } \\
\text { motorcyclist } \\
\text { committing } \\
\text { another failure }\end{array}$ & $\%$ \\
\hline Perception & 171 & 72.5 & 108 & 61.0 \\
Diagnosis & 21 & 8.9 & 8 & 4.5 \\
Prognosis & 7 & 3.0 & 20 & 11.3 \\
Decision making & 32 & 13.6 & 37 & 20.9 \\
Action taking & 0 & 0.0 & 1 & 0.6 \\
Overall failure & 5 & 2.1 & 3 & 1.7 \\
Total & 236 & 100 & 177 & 100 \\
\hline
\end{tabular}

3.2 Motorists confronted with a motorcyclist's prognosis failure

\subsubsection{Types of failure}

It was noted in a previous research work [3] that motorists are more often subject to misperceptions when they are confronted with a PTW than another opponent, whatever the circumstances. We can remark here (Table 7) that this is even more the case when the PTW rider met by the motorist commits a prognosis error (72.5\%) than for another type of error on his part $(61.0 \%)$. In the latter case, car drivers commit more often a failure of prognosis or decision making.

\subsubsection{Level of involvement}

Car drivers confronted with a motorcyclist committing a prognosis failure are significantly more often originating the conflict with the PTW (87.4\% of the cases) than when the PTW is subject to another failure (63.4\%). In this last case, the driver is considered 'no contributing' in $22.2 \%$ of the cases, which means that the problem of interaction is more often unilaterally initiated by the PTW rider when he is not subject to a prognosis error (Table 8).

\subsubsection{Factors of driving failures}

An overall analysis of factors of failure of motorists confronted with a rider committing an error of prognosis reveals three categories of items.

Table 8: Level of involvement of car drivers.

\begin{tabular}{lcccc}
\hline Level of involvement & $\begin{array}{c}\text { Confronting a } \\
\text { motorcyclist } \\
\text { committing a }\end{array}$ & $\%$ & $\begin{array}{c}\text { Confronting a } \\
\text { motorcyclist } \\
\text { committing } \\
\text { prognosis failure }\end{array}$ & $\%$ \\
\hline $\begin{array}{l}\text { Primary contributing } \\
\begin{array}{l}\text { Secondary } \\
\text { contributing }\end{array}\end{array}$ & 235 & 87.4 & 137 & 63.4 \\
No contributing & 17 & 6.3 & 31 & 14.4 \\
Total & 1 & 6.3 & 13 & 22.2 \\
\hline
\end{tabular}


A first set corresponds to problems related to the attention resources that car drivers dedicate to the traffic situation. This involves on the one hand 'inattention' which refers to a low level of resources given to the driving task, without real diversion by a secondary activity (20.6\% of cases). It encompasses on the other hand 'stereotypic information taking', which consists in watching mechanically without really paying attention to what is looked at (21\% of cases). The combination of these two factors results in a problem of attention contributing to $48.9 \%$ of the cases studied versus $31.2 \%$ when the PTW rider commits a non-prognosis error.

In line with this result, the factor 'over experience' of the car driver is more often noted $(25.4 \%)$ when the opponent rider is victim of a prognosis failure, this experience pushing to drive in a more or less automatic manner, making him inapt to detect the PTW or to behave correctly in front of it.

And a last element which plays an important role on the failures of car drivers in this kind of accidents is the poor visual saliency of the PTW (37.5\%), notably contributing to failures of perception and evaluation of the gap (Table 9).

Table 9: Most frequent factors of car drivers' failures.

\begin{tabular}{|c|c|c|}
\hline & $\begin{array}{c}\text { Confronting a } \\
\text { motorcyclist } \\
\text { committing a } \\
\text { prognosis failure } \\
(\%)\end{array}$ & $\begin{array}{c}\text { Confronting a } \\
\text { motorcyclist } \\
\text { committing } \\
\text { another failure } \\
(\%)\end{array}$ \\
\hline Inattention & 20.6 & 11.5 \\
\hline Distraction & 6.6 & 6.9 \\
\hline Stereotypic information taking & 18.4 & 10.1 \\
\hline Over experience of the situation & 25.4 & 17.5 \\
\hline Rigid attachment to right of way & 3.3 & 7.3 \\
\hline Temporal constraint & 18.4 & 14.2 \\
\hline Banalization of the situation & 9.9 & 11.5 \\
\hline Illusion of visibility (believe to be seen by others) & 3.3 & 6.9 \\
\hline Vehicle blind spot & 5.1 & 7.3 \\
\hline Difficulty to find a gap (traffic speed and density) & 9.6 & 7.3 \\
\hline Obstruction to visibility & 10.3 & 24.8 \\
\hline Poor visual saliency of the protagonist & 37.5 & 23.4 \\
\hline Surprising manoeuvre by other road user & 1.8 & 5.0 \\
\hline Illegal manoeuvre by other road user & 3.7 & 12.4 \\
\hline $\begin{array}{l}\text { 'Following' effect (indication from passenger, } \\
\text { movement from a vehicle, etc.) }\end{array}$ & 3.3 & 7.8 \\
\hline Atypical acceleration by the other & 6.3 & 4.6 \\
\hline Atypical overtaking by the other & 14.2 & 17.9 \\
\hline Atypical positioning on the lane by the other & 7.0 & 4.1 \\
\hline
\end{tabular}




\section{CONCLUSION}

An accident is a highly complex process that cannot be reduced to the intervention of a single factor. To bring operational results, accident analysis should therefore not be confined to the search for responsibility but should take into account the participation of all actors, the difficulties they encountered and the factors of these difficulties. The most typical scenario of urban accidents involving PTWs, results as was shown from a faulty interaction with a driver, highlights two joined failures: a failure of prognosis from the motorcyclist that combines with a failure of perception on the part of the motorist. Both types of failures contribute to the genesis of an accident, where one of them might have only caused a traffic conflict.

To reduce the impact of such problems, a first vector of action is to educate motorcyclists and motorists on the specific precautions to take vis-à-vis each other. These problems also call for actions on infrastructure and traffic management that favour mutual perception of road users and the predictability of their behaviour so that drivers see each other; not only the obstacles to visibility in the vicinity of intersections (buildings, traffic signs, parked cars, vegetation, etc.) must be removed, but complicated infrastructure that creates a dispersion of attention must also be avoided so that drivers are not surprised; homogeneity of speeds, notably with actions of traffic calming that take into account the particularities of each, must be promoted.

PTWs represent a key challenge for road safety improvements where progress is needed. The specificity of accident mechanisms between them and other road users, especially in urban traffic, shows the need for action in favour of improving the harmony of interactions between the different users moving in the same space.

\section{REFERENCES}

[1] ITF/OECD, Improved Safety for Motorcycles, Scooters and Mopeds Riders, OCDE: Paris, 2015.

[2] ONISR, La sécurité routière en France, bilan de l'accidentalité de l'année 2014, La documentation Française: Paris, 2015.

[3] Van Elslande, P., Les Deux-roues motorisés: nouvelles connaissances et besoins de recherche, Les Collections de l'INRETS: Bron, 2009.

[4] DACOTA, Traffic safety basic fact 2010: Motorcycles and mopeds, http://www.dacotaproject.eu/index.html [Accessed 10 February 2016].

[5] Van Elslande, P. Fournier, J.-Y. \& Parraud, C., Powered two-wheelers in urban environment: A detailed accident analysis. International Journal of Safety and Security Engineering, 5(4), pp. 322-335, 2015. DOI: 10.2495/SAFE-V5-N4-322-335

[6] Van Elslande, P., Naing, C. \& Engel, R., Analyzing human factors in road accidents. TRACE European Project, Deliverable 5.5, www.trace-project.org [Accessed 8 March 2016].

[7] OECD, Road Accidents: On-site Investigations, Road Transport Research Program, OECD: Paris, 1988. 